\title{
Role of videolaryngoscopy in patients with hoarseness of voice
}

\author{
Nehal Vindrani ${ }^{1 *}$, Monika Patel ${ }^{2}$, Sushil Gaur ${ }^{3}$, Vandana Singh $^{4}$ \\ ${ }^{1}$ Post Graduate Student, ${ }^{2}$ Assistant Professor, ${ }^{3}$ Associate Professor, ${ }^{4}$ Professor and Head, Dept. of ENT, Santosh Medical College and \\ Hospital, Ghaziabad, Uttar Pradesh, India
}

*Corresponding Author: Nehal Vindrani

Email: nehalvindrani90@gmail.com

\begin{abstract}
Introduction: Hoarseness is roughness of voice resulting from variations of periodicity or intensity of consecutive sound waves. Hoarseness is a symptom, not a disease per se therefore warrants a careful determination of the underlying cause in every case. Videolaryngoscopy is a very useful and effective method of evaluation and documentation of pathological conditions of the larynx.

Aims and Objectives: The aim of the study is to evaluate the diagnostic value of videolaryngoscopy in laryngeal pathologies.

Materials and Methods: An observational cross sectional study was carried out in the Department of ENT, tertiary level care Hospital, Ghaziabad, Uttar Pradesh. 106 patients presenting with hoarseness were included. All the patients were thoroughly evaluated and analyzed using video laryngoscopy.

Result: Among 106 cases, age ranged between 12 and 80, 47 (44.4\%) were males, largest group of patients were labourer / farmer (33\%) followed by housewives (30\%). In males, largest group was of labourer/farmer $(54.10 \%)$. Vocal abuse was the most common predisposing factors in $30 \%$ of hoarseness. Other factors in descending order were smoking (26\%), upper respiratory tract infection, and alcohol (10\%), tobacco chewing (5\%). It was found 76\% patients had single risk factor, $20 \%$ had two and $4 \%$ patients had multiple predisposing factors.

Conclusion: A good videolaryngoscopy is a definitive investigation tool where stroboscopy cannot be done. It can provide accurate diagnosis in many laryngeal pathologies. Seeing is believing. Another useful advantage of videolaryngoscopy is that the patients are able to see the pathology which helps in their counselling and better compliance of patients is seen.
\end{abstract}

Keywords: Hoarseness, Videolaryngoscopy, Vocal cord, Stroboscopy, Vocal nodule.

\section{Introduction}

Hoarseness of voice is a symptom, not a diagnosis and therefore warrants a careful determination of the underlying cause in every case. It is one of the commonest symptoms in otolaryngological practice and it indicates diseases ranging from totally benign condition to the most malignant condition. Depending on the diagnosis treatment varies from simple voice rest to aggressive treatment for certain conditions. Thus, early diagnosis of underlying cause is of utmost importance. Hoarseness is a vague term that is used to describe a change in quality of voice ranging from voice harshness to voice weakness. ${ }^{1}$ Hoarseness lasting longer than two weeks must be evaluated completely. ${ }^{2}$ Patients with hoarseness may experience discomfort with speaking, increased phonatory effort, weak voice, as well as altered quality such as wobbly or shaky voice, breathiness, and raspiness. ${ }^{3}$ At times hoarseness is often the first and only signal of serious local or systemic disease. ${ }^{4}$

Videolaryngoscopy is a very useful and effective method of evaluation and documentation of pathological conditions of the larynx. It is of great value for making accurate diagnosis and planning proper treatment. ${ }^{5}$ Videolaryngoscopy is a non-invasive and easy OPD procedure for the diagnosis of a wide range of laryngeal pathologies.

\section{Aims and Objectives}

To study the clinicopathological profile of patient presenting with hoarseness of voice. To find out association of common predisposing factors leading to hoarseness and usefulness of videolaryngoscopy for the same.

\section{Materials and Methods}

An observational cross sectional study was carried at the department of ENT and Head \& Neck surgery, at a Tertiary Level Care Hospital, Ghaziabad from June 2018 to April 2019. A total of 106 patients of the age group 10-80 years who are willing to participate were included in study. Patients not willing to participate or not given consent for the study or the female patients with ongoing pregnancy were exluded from the study. A written informed consent was obtained from the patients and their guardians wherever the patients were minor. All patients underwent complete preliminary work-up, including detailed otorhinolaryngologic examination and relevant investigations. Videolaryngoscopy using a 70 degree rigid endoscope was done in all the patients and results interpreted by a single person to reduce inter-observer variability. Data collection and entry was done using the MS - Excel and the variables identified were analyzed. Descriptive statistical analysis was carried out in the present study.

\section{Results}

Among 106 cases, 47 (44.4\%) were males and 59 (55.6\%) were females. Age ranged between 12 and 80 years. Female predominance was observed with male to female ratio of 0.8:1 (Table 1). Largest group of patients were labourer / farmer $(33 \%)$, housewives $(30 \%)$, private job/businessman (16\%), student $(9.43 \%)$, teacher $(9.43 \%)$, singer $(3 \%)$ (Table 2). In males, largest group was of labourer/farmer $(54.10 \%)$. In females, housewives $(76.92 \%)$ comprised of largest group. 
Koufman and Isaacson ${ }^{6}$ evolved a classification of vocal professionals based on their voice use and risk. Level I (elite vocal performers): Included sophisticated voice users like the singers and actors, where even a slight vocal difficulty causes serious consequences to them and their careers (3\%). Level II (professional voice users): For whom moderate vocal difficulty would hamper adequate job performance. Clergymen, politicians, public speakers, and telephone operators would classify in this level of voice users (25\%). Level III (nonvocal professionals): It includes teachers and lawyers. They can perform their jobs with slight or moderate voice problems; only severe dysphonia endangers adequate job performance (9\%). Level IV (nonvocal/ nonprofessionals): which include labourers, homemakers and clerk (63\%). These are the persons who are not impeded from doing their work when they experience any kind of dysphonia.

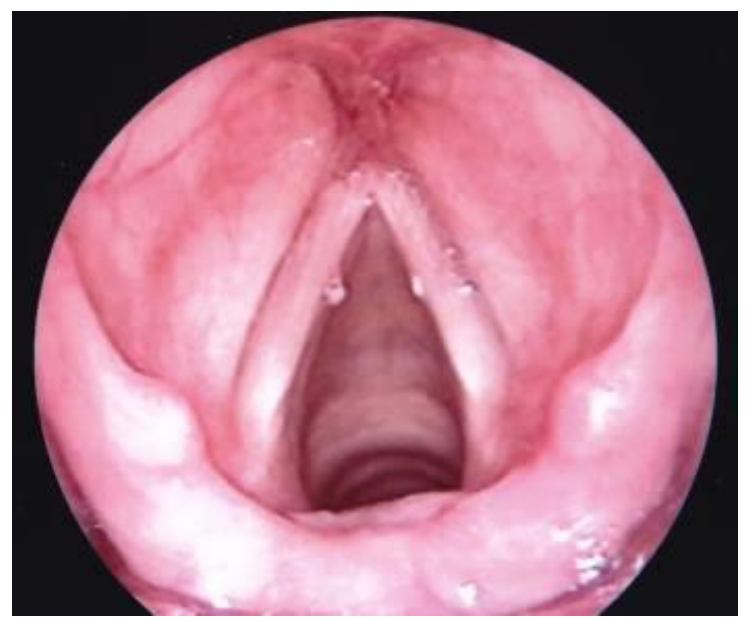

Fig. 1: Image showing bilateral vocal nodules in a 35 year old patient who was a teacher by profession

Vocal abuse was the most common predisposing factors in $30 \%$ of hoarseness. Other factors in descending order were smoking (26\%), upper respiratory tract infection, and alcohol (10\%), tobacco chewing (5\%). In about $15 \%$ no predisposing factor was found (Table 4). Some patients had more than one predisposing factors. We found $76 \%$ patients had single risk factor, $20 \%$ had two and $4 \%$ patients had multiple predisposing factors. Few patients had two or more than two complaints at the time of examination. Along with hoarseness, patients presented with foreign body sensation in throat, dysphagia and dyspnoea. Duration of symptoms ranged from two days to more than a year. Mean presentation of complaints was of two months.

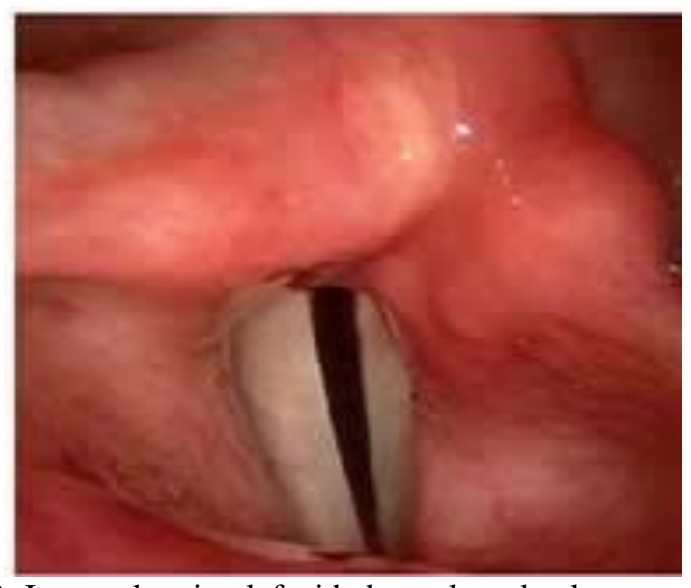

Fig. 2: Image showing left sided vocal cord palsy

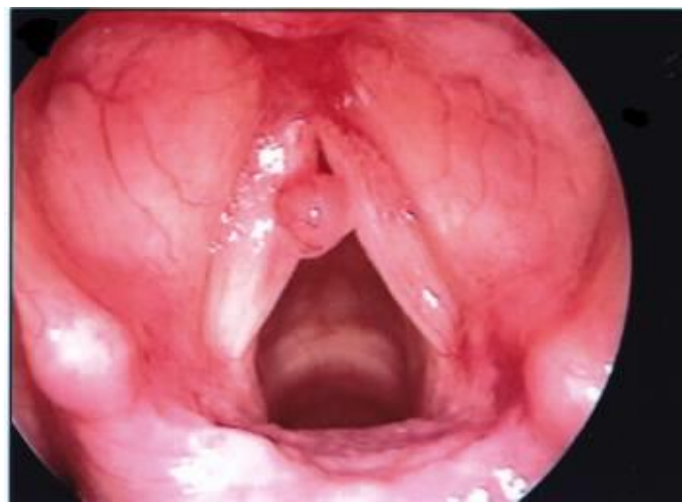

Fig. 3: Image showing right vocal cord polyp.

Table 1: Demographic distribution of patients

\begin{tabular}{|l|c|c|c|}
\hline \multirow{3}{*}{ S. No. } & $\begin{array}{c}\text { Demographic } \\
\text { Character }\end{array}$ & Number & $\begin{array}{c}\text { Percentage } \\
(\mathbf{\%})\end{array}$ \\
\hline \multirow{4}{*}{1} & \multicolumn{3}{|c|}{ Age Wise } \\
\cline { 2 - 4 } & $12-20$ & 7 & 6.6 \\
\cline { 2 - 4 } & $21-30$ & 14 & 13.2 \\
\cline { 2 - 4 } & $31-40$ & 25 & 23.5 \\
\cline { 2 - 4 } & $41-50$ & 20 & 18.8 \\
\cline { 2 - 4 } & $51-60$ & 18 & 17.0 \\
\cline { 2 - 4 } & $61-70$ & 18 & 17.0 \\
\cline { 2 - 4 } & $71-80$ & 4 & 3.8 \\
\hline \multirow{4}{*}{2} & Total & 106 & 100 \\
\cline { 2 - 4 } & \multicolumn{3}{|c|}{ Gender } \\
\cline { 2 - 4 } & Male & 47 & 44.4 \\
\cline { 2 - 4 } & Female & 59 & 55.6 \\
\cline { 2 - 4 } & Total & 106 & 100 \\
\hline
\end{tabular}

Table 2: Showing occupation wise distribution

\begin{tabular}{|l|c|c|c|}
\hline S. No. & Occupation & Number & Percentage \\
\hline 1 & Farmer/labourer & 35 & 33.03 \\
\hline 2 & Housewife & 32 & 30.19 \\
\hline 3 & Businessman & 16 & 15.09 \\
\hline 4 & Student & 10 & 9.43 \\
\hline 5 & Teacher & 10 & 9.43 \\
\hline 6 & Singer & 3 & 2.83 \\
\hline \multicolumn{2}{|l|}{ Total } & $\mathbf{1 0 6}$ & $\mathbf{1 0 0 . 0 0}$ \\
\hline
\end{tabular}


Table 3: Various pathologies causing hoarseness of voice

\begin{tabular}{|l|c|c|c|c|}
\hline S. No. & Pathology & Male (N) & Female (N) & Total N (\%) \\
\hline 1 & Haemorrhagic Vocal Cord & 3 & 7 & $10(9.4)$ \\
\hline 2 & Vocal Cord Palsy & 10 & 6 & $16(15.1)$ \\
\hline 3 & Vocal Nodule & 10 & 15 & $25(23.5)$ \\
\hline 4 & Vocal Polyp & 7 & 4 & $11(10.3)$ \\
\hline 5 & Vocal Cysts & 5 & 4 & $9(8.4)$ \\
\hline 6 & $\begin{array}{c}\text { Chronic Nonspecific } \\
\text { Laryngitis }\end{array}$ & 7 & 13 & $20(18.8)$ \\
\hline 7 & Acute Laryngitis & 4 & 6 & $10(9.4)$ \\
\hline 8 & Malignancy & 4 & 1 & $5(4.7)$ \\
\hline Total & & $\mathbf{5 0}$ & $\mathbf{5 6}$ & $\mathbf{1 0 6}(\mathbf{1 0 0 . 0})$ \\
\hline
\end{tabular}

Table 4: Showing distribution of common predisposing factors

\begin{tabular}{|l|c|c|c|}
\hline S. No. & Predisposing factors & Number & Percentage \\
\hline 1 & Vocal abuse & 32 & 30.19 \\
\hline 2 & Upper Respiratory Tract Infections & 20 & 18.87 \\
\hline 3 & Smoking & 27 & 25.47 \\
\hline 4 & Alcohol & 10 & 9.43 \\
\hline 5 & Tobacco chewing & 6 & 5.66 \\
\hline 6 & No factors & 11 & 10.38 \\
\hline \multicolumn{2}{|c|}{ Total } & $\mathbf{1 0 6}$ & $\mathbf{1 0 0 . 0 0}$ \\
\hline
\end{tabular}

\section{Discussion}

Although there was a male predominance in many previous studies, here in this study we found a female predominance with male to female ratio of $0.8: 1 .^{7,8}$

Professionals with higher risk of voice problems were singers, teachers, lawyers, hawkers as seen in other studies. ${ }^{9,10}$

In present study it was also noted that housewives, especially mothers of small kids had hoarseness. This may be due to chronic screaming habits at home.

Most common pathology was vocal cord nodules $(23.5 \%)$ most of the vocal cord palsy were idiopathic $(15 \%)$ and on the left side which is consistent with other studies. ${ }^{11}$

Few patients $(4.7 \%)$ with chronic progressive voice disorders were diagnosed to have malignancy (Table 3). These were usually associated with symptoms like dysphagia, foreign body sensation, and were chronic tobacco users. All elderly male patients with tobacco habits presenting with changes in voice for more than two weeks should be evaluated to rule out malignancy.

Majority of patients especially females were diagnosed to have chronic laryngitis. The most common findings were congestion in posterior larynx, string sign positive, in some severe cases granuloma were seen in posterior larynx.

\section{Conclusion}

Videostroboscopy is the most ideal method for evaluation of vocal cord vibration and mucosal waves. ${ }^{12}$

Although a painless, office based procedure, at times is not available in many setups and also is a costly affair.

On the contrary video laryngoscopy with 70 degree endoscope is also painless, office based procedure to evaluate hoarseness. A careful videolaryngoscopic examination can be of great importance in accurately diagnosing laryngeal pathologies. Selected cases can be further evaluated by stroboscopy.

Hence, it conclude that a good videolaryngoscopy is a definitive investigation tool where stroboscopy cannot be done. It can provide accurate diagnosis in many laryngeal pathologies.

Seeing is believing. Another useful advantage of videolaryngoscopy is that the patients are able to see the pathology which helps in their counseling and better compliance of patients is seen.

\section{Source of funding}

Self.

\section{Conflicts of interest}

None declared.

\section{References}

1. Loyn SB. Doctor my voice seems husky. Auster Fam Physician 1994;23:2111.

2. Rosen CA, Anderson D, Murry T. Evaluating hoarseness: keeping your patient's voice healthy. Am Fam Physician 1998;57(11):2775-82.

3. Scott S, Robinson K, Wilson JA. Patient reported problems associated with dysphonia. Clin Otolaryngol Allied Sci 1997;22:37-40.

4. Von Leden H. The electric synchro-stroboscope: its value for the practicing laryngologist. Ann Otol Rhinol Laryngol 1961;70:881-93.

5. Yanagiswa E. Videolaryngoscopy, A comparison of fiberscopic and telescopic documentation, Ann Otol Rhinol Laryngol 1983;92(5Pt 1):430-6.

6. Koufman J, Isaacson G (eds) (1991). The spectrum of vocal dysfunction. The otolaryngologic clinics of North America: voice disorders. WB Saunders, Philadelphia, p 47. 
7. Baitha S, Raizada RM, Kennedy Singh AK, Puttewar MP, Cha- turvedi VN. Clinical profile of hoarsens of voice. Indian J Otolaryngol Head Neck Surg 2002;54(1):14-8.

8. Batra K, Motwani G, Sagar PC. Functional voice disorders and their occurrence in 100 patients of hoarseness as seen on fibreoptic laryngoscopy. Indian J Otolaryngol Head Neck Surg 2004;56(2):91-5.

9. Fritzell B. voice disorders and occupation. Log Phon Vocol 1996;21:7-12.
10. Titze IR. The Myoelatic Aerodynamic Theory of Phonation. Iowa city: National Center for Voice and Speech; 2006.

11. Banjara H, Mungutwar V, Singh D, Gupta A, Singh S.

Demographic and videostroboscopic assessment of vocal pathologies. Indian J Otolaryngol Head Neck Surg 2012;64:150-7.

12. Bless DM, Hirano M, Feder RJ. Videostroboscopic evaluation of the larynx. Ear Nose Throat J 1987;66:289-96. 